The University of Akron

\title{
IdeaExchange@UAkron
}

Proceedings from the Document Academy

University of Akron Press Managed

January 2016

\section{For Every Document, a Person: A Co-Created View of Documents}

Tim Gorichanaz

Drexel University, gorichanaz@drexel.edu

Please take a moment to share how this work helps you through this survey. Your feedback will be important as we plan further development of our repository.

Follow this and additional works at: https://ideaexchange.uakron.edu/docam

Part of the Library and Information Science Commons

\section{Recommended Citation}

Gorichanaz, Tim (2015) "For Every Document, a Person: A Co-Created View of Documents," Proceedings from the Document Academy: Vol. 2 : Iss. 1 , Article 9.

DOI: https://doi.org/10.35492/docam/2/1/9

Available at: https://ideaexchange.uakron.edu/docam/vol2/iss1/9

This Conference Proceeding is brought to you for free and open access by University of Akron Press Managed at IdeaExchange@UAkron, the institutional repository of The University of Akron in Akron, Ohio, USA. It has been accepted for inclusion in Proceedings from the Document Academy by an authorized administrator of

IdeaExchange@UAkron.For more information, please contact mjon@uakron.edu, uapress@uakron.edu. 
For Every Document, a Person:

A Co-Created View of Documents

Reading a book in one's youth is like looking at the moon through a crevice; reading a book in middle age is like looking at the moon in one's courtyard; and reading a book in old age is like looking at moon on an open terrace. This is because the depth of benefits of reading varies in proportion to the depth of one's own experience.

-Zhang Chao, On Books and Reading, 18th century

\section{Introduction}

It has long been understood that context is important to the concept of document. Suzanne Briet (1951/2006) famously asserted, for example, that an antelope in the wild is not a document, but an antelope in the zoo is. Could it be the case, then, that a book being read is a document, but a book alone in a forest is not? Michael Buckland (2014) seems to have concluded as much, suggesting that any object can assume documentary characteristics in a context that affords it; conversely even a paragon document, such as a printed book, can cease to be a document if used only as a doorstop.

But what contexts afford documents? This article presents a conceptual analysis (Furner, 2004) of document which demonstrates that documentary status, as conceptualized by an array of researchers, requires the activity of a human being. Humans are vital to documents. That is, a human being is inextricable from the very notion of document. Though long implied, it seems this has thus far not been articulated explicitly. From this understanding, a conceptualization of documents as co-created can be framed.

Such a discussion has many important ramifications. First, it bounds (or perhaps unbounds) the discipline of document studies in a potentially useful way by illuminating what is and is not within its purview. Relatedly, it highlights applications for research and the philosophy of information. It also serves to communicate to fields within and around the vast realm of information research the vital (not just tangential) importance of human beings- "resurrecting the human" in information science, as called for by Buckland (2003). Finally, it begs the question of what necessary and sufficient conditions are required (beyond a human actor) to form a document, and it prompts us to consider the future of documentation as the line between human and non-human begins to blur. 


\section{Documents as Part-Human and Co-Created}

Information studies began with the document, at first only loosely defined, as its object of study (Bawden \& Robinson, 2012, pp. 75-78). This concept continues to be fundamental to and shared by a panoply of allied areas of academic inquiry, including library studies, archives and museum studies. Perhaps impelled by the centrality of the concept, scholars have struggled for decades to determine a definition of document that would satisfy its diverse constituents. In so doing, these scholars have implicitly been seeking determination regarding what is and is not within the scope of information studies. Implicit in this discussion is the notion that something might be informative while not being a document.

Context is understood to be important in determining whether something is a document. Bernd Frohmann wrote that "things are documents when located in places where they are readily available to provide evidentiary support for particular propositions" (2009, p. 297). Later, Buckland wrote that "any object that has documentary characteristics [is] a document; but, of course, that does not mean that it should be considered always and only in this way" (2014, p. 185). But what sorts of contexts afford documents? Context, after all, can be understood in an infinitude of ways (Dey, 2001).

In chronicling the concrete definitions of document that have been put forth over the years, we consider:

- Paul Otlet's objects that are informative upon observation (as cited in Buckland, 1997, p. 805),

- an unnamed bibliographer's "proof in support of a fact" (as cited in Briet, 2006, p. 9),

- the French Union of Documentation Organizations" "all bases of materially fixed knowledge, ... capable of being used for consultation, study, and proof' (as cited in Briet, 2006, p. 10),

- Briet's own "any concrete or symbolic indexical sign, preserved or recorded toward the ends of representing, of reconstituting, or of proving a physical or intellectual phenomenon" (2006, p. 10),

- S. R. Ranganathan's "embodied micro thought" on material "fit for physical handling, transport across space, and preservation through time" (as cited in Buckland, 1997, p. 807),

- the International Institute for Intellectual Cooperation's "any source of information, in material form, capable of being used for reference or study or as an authority" (as cited in Buckland, 1997, p. 805), and 
- the OED's "something written, inscribed, etc., which furnishes evidence or information upon any subject, as a manuscript, title-deed, tomb-stone, coin, picture, etc.” (Document, n., 2015).

It should also be noted that the very prospect of defining document has been called into question. Frohmann (2009) argues that doing so is philosophically unjustified and unnecessarily limiting. He first suggested that document should be defined not by anything inherent in objects themselves, but rather by the practices surrounding their use and their capacity to furnish information: materiality, institutionalization, social discipline and historicity (Frohmann, 2004). More recently he has suggested that analogy and other rhetorical techniques can be used to tell stories that extend the idea of document from prototypical examples - that is, the most central category members - of documents to novel ones (Frohmann, 2009).

Implicit in all the definitions of document recounted above is the presence and activity of at least one human being. Without a human actor, an object cannot be observed, consulted or studied, and there is nobody to judge proof, be presented to, reconstitute, handle, transport or preserve. With this in mind, a vital part of any context that affords documents is the activity of a human being. If there is no person involved, a book is nothing more than a weighty collection of inked leaves - it is not a document. An information object by itself is but a potential document. Once a person uses it, a document is created.

Figure 1. The co-created document and the human's transaction experience.

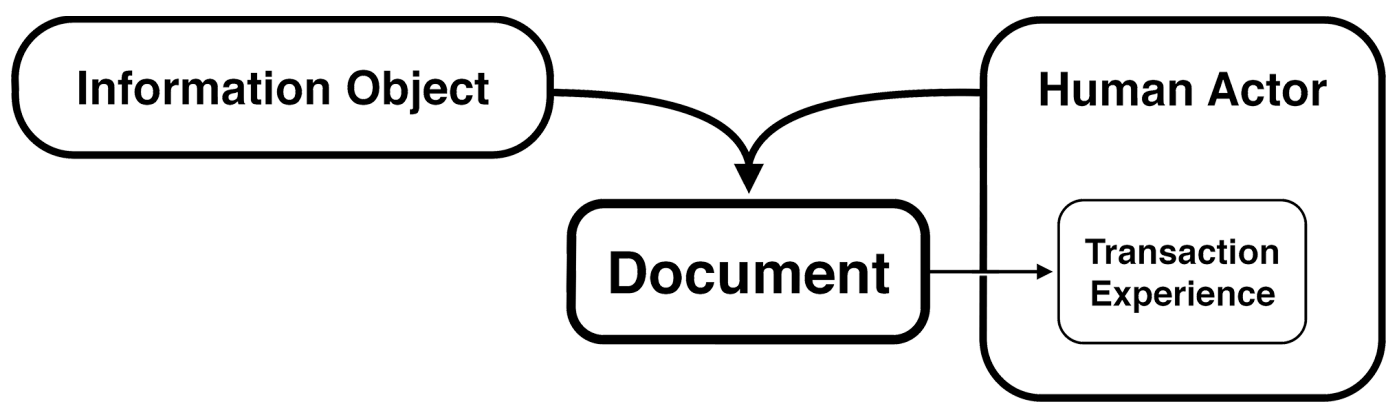

If it is accepted that a document is created only with a human actor, it follows that the human actor must be considered inextricable from the document. We can thus conceptualize documents as co-created (Figure 1); both the information object and the human actor contribute to the formation of a document. This occurs in a transaction, as described by K. F. Latham (2014). 
According to Latham's conceptual model, document transactions result in experiences that can be located along the efferent-aesthetic continuum, borrowed from Louise Rosenblatt, in which efferent experiences are characterized by extraction for later use, and aesthetic experiences are of-the-moment.

The co-created understanding of document has an important ramification: Documents do not exist in the physical world, but rather in a psycho-physical or socio-physical realm. The co-created document arises from the relationship among the elements that afforded it (prototypically, a human and an information object). Thus all documents are idiosyncratic and context-bound. As mentioned previously, a book on its own should not be considered a document, but merely an information artifact - a potential document. But when a particular person reads a particular book, a document is born; the book's information combines with the person's mental state, life experience and other thoughts to form the document.

In consequence, anyone who deals with documents must consider how information artifacts change into documents when they are beheld by a human. Thus questions of cataloging, preservation and retrieval should recognize the human actor not only as an observer or a user, but as a co-creator. Designers of retrieved information artifacts should consider how seemingly inconsequential elements such as type and layout affect the resulting document and associated experience - and the information the user ascertains from it. This conclusion is consistent with that of Charles Bazerman (2012), who notes that documents must ultimately be oriented toward the end user, and technologies should support this orientation. But perhaps this need is stronger than has previously been considered.

\section{Research Applications}

Much of the research in information studies has focused on questions of information organization, literacy and retrieval (Bawden \& Robinson, 2012). However important these foci may be, they tend to ignore the in-the-moment experience of humans interacting with information. Understanding the human experience of information seems vital, given that we access documents through such experiences. Documents themselves may exist in a relational realm, but the only way we can appreciate a given document is by means of sensory perception, governed by the brain and nervous system. (Even an imagined document would, at least from a materialist perspective, arise from nervous system activity.)

A recent volume has begun to address this gap, presenting an overview of the research in information experience (Bruce, Davis \& Hughes, 2014). This work

represents advances in our understandings of human attitudes toward and 
perceptions of information in various contexts. More research in this area may support the development of a typology of document experiences based on the characterization of the transaction that occurs between a human and an information object in the formation of a document. If we are to have a complete understanding of what documents are, researchers must investigate further the experience of documents from diverse perspectives. This line of research cloud strengthen ties between information science and other disciplines. Closer to home, this perspective may also serve as a reminder to researchers in more traditional areas of information studies that idiosyncratic human beings are co-creators in the use of information systems.

This discussion also raises moral and ethical questions. All information objects are important (not only those which encapsulate human experiences), because they are in themselves potential human experiences. Digitizing a book, for example, may seem to devalue the print version. But if the experience between these versions is qualitatively different, then both are valuable for different reasons. What might it mean for a person to only have access to one or the other? Luciano Floridi (2002) has asserted that information objects have intrinsic value and are thus subject to moral respect. The conceptualization of documents as cocreated and part-human strengthens this claim because all information objects must be seen as potentially part-human.

Finally, this conceptualization invites us to consider documents from the perspective of the information objects, rather than simply that of the human. From the perspective outlined above, we can understand that we access documents through our experience of transactions. Presumably the information object experiences an analogous transaction; this argument has also been advanced from the burgeoning perspective of object-oriented ontology (Harman, 2002). We do not presently have access to the object's document experience, but it would seem prudent to develop research in this area. Indeed, this has already been identified by researchers in the philosophy of information. Betsy Van der Veer Martens, for example, highlights "the unique opportunity to consider the open question of the document or the record from the point of view of the document or record itself" (2015, p. 344). This is also consistent with Ron Day's "Death of the User," which promotes a subject-object view of information access. "All beings and things have certain powers, receptivity, and resistances to be affected and to affect in relation to other beings and things, depending on their ontological properties and how this is shaped by experience" (Day, 2011, p. 81). Addressing the human experience of documents, then, not only bridges an important gap in information 
studies, but also opens the door to a more sophisticated understanding of information generally.

\section{Documents Without Humans?}

The conceptualization advanced in this paper has identified human activity as a vital component of a document. But is a human actor strictly necessary? And what might this mean in a world where human and object begin to blur?

As described above, the prototypical document arises from the fusion of a human and an information object (e.g., a person reading a book), but more broadly the "object" could be any non-human entity, including those we do not generally consider to be "objects" (e.g., an antelope in a zoo). A document may also reasonably result from a human-human fusion (e.g., a wedding kiss). This is , for instance, reflected in Annemaree Lloyd's (2010) corporeal information, which recognizes the body as an information source, and Deborah Turner's (2012) oral document, which argues that person-to-person verbal communications can be documental. Discussions have not yet considered, however, that a document could result from an object-object fusion (or that of any two non-humans).

This seems to present a boundary for information studies, which may be welcomed by those who see the discipline as overly sprawling (e.g., White, 1999). But is this a warranted conceptual boundary, or is it an artifact of our privileging of humanity? After all, what Briet (2006) really meant in asserting that an antelope in the wild is not a document was that an antelope in the wild is not a document for a human. Surely the same wild antelope would function as a document to a hungry lion, just as the label on a container of yogurt is a document to a hungry human.

Information, after all, encompasses much more than what has traditionally been considered by information scientists:

- Computer components send informative impulses to other components, which allows the machine to function.

- Throughout our bodies, information is dispatched to elicit hormonal responses to actions we take.

- Bees find food by interpreting the markings on flowers.

Are these examples of documents? More concretely, are these topics to which information studies has something to contribute, or should they be the sole purview of other disciplines, such as computer engineering, endocrinology and zoology? 
To complicate matters, the digital age has occasioned new types of document-like things that beg discussion. As observed by Buckland (2014), a key card can be documentary in its capacity to inform a human being. But is it also documentary when it is read by a machine that triggers a door to open? Barcodes, also, are used in machine-machine communication in a way that is not fully appreciable by humans. Are such issues appropriate for information science to address, or should information science be limited to documents as beheld by humans?

It may be tempting to think that anything that informs-regardless of whether a human is involved - could reasonably be considered a document. But the traditional documentalist might argue (with Briet) that, because any document is inextricable from its context, because we are humans and therefore understand best human contexts, and because the ends of information science as a discipline relate to human endeavors, we might conclude that we should only truly consider documents those things that inform humans.

On these grounds, it may be concluded that document-like things (which have all the properties of documents except the presence of a human) that inform computers, animals, and even the cellular and molecular components of humans themselves, such as barcodes, urine markings and DNA, are not documentsthough they may contain information - and that they should be examined in disciplines outside information studies. However, this isn't to say that these things could not be analyzed as documents to some end, to the extent that humans can interact with them. Major corporations, for instance, manage millions upon millions of barcodes: Each product has one, each parcel shipped has one, and they also find their way onto invoices, gift cards and more. For the most part, barcodes are generated by computers for use by computers. The system that allows this to happen, which is made and maintained by humans, could be considered a document insomuch as humans behold it. And though the barcodes themselves seem to have some of the characteristics of documents, the current conceptualization of document would prohibit them from being considered documents until they transact with a human being ${ }^{1}$.

But again we must question whether the distinction between human and non-human in our conceptualization of document is warranted. Even if it is today, will it continue to be in the future? If we maintain that a human is a requisite

\footnotetext{
1 This brings up an interesting question: What happens when a human interacts with an information object that was "meant" for a non-human? For example, how do humans experience technology-enabled displays showing biometric information that is usually imperceptible? Information art (Karamuftuoglu, 2006) presents a foray into this area.
} 
component for document-making, what happens as the line between human and non-human blur?

Scholars such as Ray Kurzweil (2005) and Nick Bostrom (2014) predict the impending technological singularity. According to Kurzweil, technological evolution will have outpaced biological evolution within a matter of decades, and the sum of human intelligence will pale in comparison to machine intelligence. In the predicted world, devices will be cognitively and emotionally indistinguishable from biological humans. Devices will be able to design, improve and produce their own progeny, which will be ever more advanced than humans, and these devices will have complete autonomy in the world. Biological humans will be able to harness this technology to alter their bodies, augment their abilities and extend their lives.

Even today, the line between human and machine is becoming blurry. Many of us wear glasses or have smartphones. Some of us have pacemakers and prosthetic limbs. Many of us participate in medical interventions. These devices and procedures support and enhance our biological capabilities, such as vision and memory. Do humans who are supported by new technology become less human as a consequence? Today, the question may seem silly-even offensive. But singularitarians (Kurzweil, 2005) portend a future where this question becomes important.

Even if the singularity is not borne out, the question begs consideration as a philosophical thought experiment in order to bolster our conceptualizations. In such a world, it would seem that documents, like machines, would no longer require humans. In a post-singularity future, object-object transactions would seem to engender documents. This may indicate that the ends of information studies as a discipline may no longer relate to human endeavors exclusively. How can this be accounted for? How can it be studied?

\section{Conclusion}

This paper has presented a conceptual analysis that reveals a common conceptualization of document as co-created, prototypically by a transaction between a human being and an information object. In light of this, information experience has been highlighted as an important area of inquiry in information studies, and a number of other ramifications for research were discussed.

This perspective serves, first and foremost, as a reminder to all information researchers and practitioners that people are the ultimate experiencers of documents. Even when designing a retrieval system, storing documents for 
retrieval should not be the only concern; bringing documents to people in a holistic way should be a key consideration. This viewpoint represents a paradigm shift in our approach to design, which has been progressing from being systemcentric to being human-centric over the past few decades (Nahl, 2009); now, we can sense the advent of a transaction-centric design approach.

Finally, this paper has raised questions for documentalists regarding the boundaries of information studies as a discipline and the role humans will play in documents in the era of the possibly impending technological singularity. 


\section{References}

Bawden, D., \& Robinson, L. (2012). Introduction to information science. Chicago: Neal-Schuman.

Bazerman, C. (2012). The orders of documents, the orders of activity, and the orders of information. Archival Science, 12(4), 377-388.

Bostrom, N. (2014). Superintelligence: Paths, dangers, strategies. Oxford: Oxford University Press.

Briet, S. (2006). What is documentation? R. E. Day, L. Martinet, \& H. G. B. Anghelescu (Trans. \& Eds.). Oxford: Scarecrow Press. (Original work published 1951)

Bruce, C., Davis, K., \& Hughes, H. (Eds.). (2014). Information experience: Approaches to theory and practice (Business, Management and Economics, Volume 9). Bradford, GBR: Emerald Group Publishing Limited.

Buckland, M. (1997). What is a "document"? Journal of the American Society for Information Science, 48(9), 804-809.

Buckland, M. (2003, October). The artificiality of documents: Or, resurrecting the human in information science. Presented at the annual meeting of the American Society for Information Science and Technology, SIG History and Foundations of Information Science, Long Beach, CA.

Buckland, M. (2014). Documentality beyond documents. The Monist, 97(2), 179186.

Day, R. E. (2011). Death of the user: Reconceptualizing subjects, objects, and their relations. Journal of the American Society for Information Science, $62(1), 78-88$.

Dey, A. K. (2001). Understanding and using context. Personal and Ubiquitous Computing, 5(1), 4-7.

Document, n. [Def. 4]. (2015, March). In OED online. Retrieved from http:// www.oed.com

Floridi, L. (2002). On the intrinsic value of information objects and the infosphere. Ethics and Information Technology 4(4), 287-304.

Frohmann, B. (2004). Documentation redux: Prolegomenon to (another) philosophy of information. Library Trends, 52(3), 387-407.

Frohmann, B. (2009). Revisiting “what is a document?". Journal of Documentation, 65(2), 291-303. doi:10.1108/00220410910937624 
Furner, J. (2004). Conceptual analysis: A method for understanding information as evidence, and evidence as information. Archival Science, 4(3/4), 233-265. Retrieved from http://works.bepress.com/furner/13

Harman, G. (2002). Tool-being: Heidegger and the metaphysics of objects. Peru, IL: Open Court.

Karamuftuoglu, M. (2006). Information arts and information science: Time to unite? Journal of the American Society for Information Science and Technology, 57(13), 1780-1793.

Kurzweil, R. (2005). The singularity is near: When humans transcend biology. New York: Viking Books.

Latham, K. F. (2014). Experiencing documents. Journal of Documentation, 70(4), 544-561.

Lloyd, A. (2010). Corporeality and practice theory: Exploring emerging research agendas for information literacy. Information Research, 15(3). Retrieved from http://www.informationr.net/ir/15-3/colis7/colis704.html

Nahl, D. (2009). User-centered revolution: 1970-1995. In M. J. Bates \& M. N. Maack (Eds.), Encyclopedia of library and information sciences (3rd ed.) (pp. 5461-5495). New York: Taylor and Francis.

Turner, D. (2012). Oral documents in concept and in situ, part I: Grounding an exploration of orality and information behavior. Journal of Documentation, 68(6), 852-863.

Van der Veer Martens, B. (2015). An illustrated introduction to the infosphere. Library Trends, 63(3), 317-361.

White, H. D. (1999). Scientist-poets wanted. Journal of the American Society for Information Science, 50(12), 1052-1053. 